\title{
Sosyal Ağlarda Güvenilir ve Güvenilmez Bireylerin Tespit Edilmesi
}

\section{Detection of Trusted and Untrusted Individuals in Social Networks}

\author{
Esra Karadeniz Köse $^{* 1}$ (iD) , Ali Karcl² \\ ${ }^{1}$ Bilgisayar Mühendisliği Bölümü, İnönü Üniversitesi, Malatya, Türkiye \\ ${ }^{2}$ Yazılım Mühendisliği Bölümü, İnönü Üniversitesi, Malatya, Türkiye \\ (esra.karadeniz@inonu.edu.tr, ali.karci@inonu.edu.tr)
}

Received: Sep.3, 2021

Accepted: Sep.16, 2021

Published: Oct.20, 2021

\begin{abstract}
Identification of trusted users or information source in social networks is one of the most important needs for reasons such as data security and privacy. In this study, the social network is modeled as a graph. Trusted and untrusted individuals in the network have been determined with the principle that if the nodes have common neighbors, these nodes are similar. Thanks to this determination, it has been possible to ensure the security of the network and to strengthen the ties with the trusted structures by taking the necessary measures for the untrustworthy structures in the network with the predicted confidence inferences.
\end{abstract}

Keywords: Social network, trust

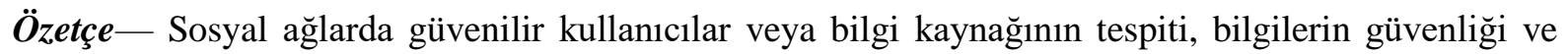
gizliliği nedeniyle birincil gereksinimlerden biridir. Bu çalışmada sosyal ağ bir çizge olarak modellenmiştir. Ağdaki güvenilir ve güvenilmeyen bireyler, düğümlerin ortak komşuları varsa bu dügümler benzerdir ilkesiyle belirlenmiştir. Bu tespit sayesinde öngörülen güven çıkarımları ile ağdaki güvenilmez yapılar için gerekli tedbirler alınarak ağın güvenliğinin sağlanmasına ve güvenilen yapılarla bağların kuvvetlendirilmesine imkan tanınmıştır.

Anahtar Kelimeler: Sosyal ağlar, güven

\section{Giriş}

Sosyal ağlar, insanlar ve örgütler arasındaki iletişim devriminde çok önemli rol oynamaktadır. Sosyal ağ tanımıyla özdeşleşen sosyal medyanın da etkisiyle insanların duyguları, etkileşimleri ve kolektif davranışları büyük ölçüde etkilenmekte ve șekillenmektedir. Günümüzde, her yeni bilgi öncelikle sosyal ağlarda ve bundan sonra geleneksel medyada yayınlanmaktadır. Dahası, kullanıcılar geleneksel medya yerine sosyal ağlardan bilgi almayı alışkanlık haline getirmişlerdir (Bruhn ve diğerleri, 2012).

Sosyal ağ, bünyesindeki elemanları temsil eden düğümler ve bu elemanlar arası ilişkiyi temsil eden bağlantılardan oluşan çizgeler olarak ifade edilebilir. Sosyal ağ kavramının artan önemi sosyal ağ yapılarının incelenip analiz edilmesi, bağlantı tahmini, duygu analizi, ağlardaki topluluklar ve toplulukların keşfedilmesi gibi konularda araştırmaları da artırmıştır. 
Sosyal ağ analizi, ağ yapılarının içerisinde yer alan düğümler arasındaki ilişkilerin farklı bilimsel yöntemler vasitasıyla ayrıntılı olarak irdelenmesiyle elde edilen verilerden anlamlı ve yorumlanabilir sonuçlar üretilmesi işine denir (Karadeniz ve diğerleri, 2018).

Bu çalışmada; ă̆ yapısı, sosyal ağ analizi, sosyal ağların gösteriminde kullanılan çizge teorisi, sosyal ağdaki tüm yolları bulmak adına çizge algoritmaları ve bireylerin birbirlerine duydukları güven oranları hesabının nasıl yapılabilineceği incelenmiştir.

\section{Temel Bilgiler}

\section{1. Çizge Teorisi ve Sosyal ağlar}

Çizge teorisi, 1736 y1lında Königsberg kasabasının "Yedi Köprü” problemine Leonhard Euler'in sunduğu çözüm ile ortaya çıkmıştır. Konigsberg bridge problemi olarak da bilinen bu problem, çizge teorisinin başlangıç problemi olarak bilinir (Biggs ve diğerleri, 1986).

Çizgeler temel bilimlerde, mühendislik dallarında ve sosyal bilimlerde problemlerin birçoğuna algoritmik çözüm olanağı sunar. Bir problemin tasviri dügümmler ve dügü̈mler arası ilişkiler olarak yapılabiliniyorsa çözümü çizgelerle oluşturulabilir.

Çizge dügüm denen noktalar ve bu noktaları birleştiren ayrıtlar bütünüdür. Şehirleri düğüm (vertice), şehirlerarası yolları ayrıt (edge) olarak tanımlayan yol haritalarını çizgeye örnek olarak verebiliriz. Bir çizgede bir veya daha fazla düğümden ve kenardan geçen rotaya $\mathrm{f}$ (path) denir.

Bir çizgeyi tanımlamak için düğümlerin ve ayrıtların kümesi tanımlanır. Düğümler arası bağlantılar belirtilir. Çizge $\mathrm{G}$ ile gösterilir ve bir $\mathrm{G}$ çizgesi, V ile gösterilen düğümlerden ve $\mathrm{E}$ ile gösterilen ayritlardan (edges) oluşur.

Sosyal ağların birçok ifade ve modelleme biçimi vardır ama literatürde yaygın olarak çizgeler kullanılır. Sosyal ağ bir çizge, ağdaki elemanlar bu çizgedeki düğümler ve elemanlar arası ilişkiler de çizgedeki ayrıtlar olarak ifade edilir. Çizgeler ve bu çizgelerden oluşturulan matrislerle çeşitli hesaplamalar yapılabilmektedir. Örneğin dügümleri kümeleme, benzerlik hesabı, bağlantı tahmini vs. ilişkiler hesaplanıp anlamlandırılabilmektedir (Boy, 2012).

\section{2. Çizgede Dolaşma}

Çizge üzerinde dolaşma, istenilen bir işi yapma veya bir probleme çözüm üretme noktasında çizgede kenarlar vasıtasıyla düğümler arası hareket edilmesidir. Çizge üzerinde dolaşmada kullanılan birçok algoritma vardır (Herman, 2000). Çizgeler üzerinde çalışan bu algoritmalara örnek olarak FloydWarshall algoritmas1, sabit maliyetli arama (uniform cost search), Dijkstra algoritmas1, Prim algoritmas1, Bellman-Ford algoritmas1, Kruskal algoritması, ikili arama ağacı (binary search tree), genişlik öncelikli arama (breadth first search (bfs)), derinlik öncelikli arama (depth first search (dfs)), b-ağaçları (b-tree) vb. verebiliriz.

Çizgede bütün düğümleri en az maliyetle gezme, belirlenen iki düğüm arası en kısa yolu bulma, tüm düğümler arası en kısa yolu bulma, iki düğüm arasındaki optimum akışı hesaplama, yol ağacının bulunması, düğüm veya bölge renklendirme, bir düğümden çıkıp gezi yapma vb. işlemler çizge dolaşmanın konusudur.

\subsubsection{DFS (Depth First Search (Derin Öncelikli Arama))}

DFS algoritması, geri besleme fikrini kullanan özyineli bir algoritmadır (Even, 2011). DFS' ün bu özyinel yapısı yığıtlar (stacks) kullanılarak uygulanabilir. Bir çizge için Derinlik Öncelikli Geçiş (veya Arama) bir ağacın derinlik öncelikli geçişine benzer. Buradaki tek fark, ağaçların aksine, çizgeler döngü içerebilir, bu yüzden aynı düğüme tekrar gelebiliriz. Bir düğümü birden çok kez işlemekten kaçınmak için ziyaret edilen düğümleri işaretleyebileceğimiz bir boolean dizi kullanırız.

DFS çizgeyi dolaşırken, derinlik olarak gidebildiği kadar gidip geri döner. DFS algoritmasında geçilen düğümler yığıta atılır. Tüm komşu düğüm ziyaretleri gerçekleşince yığıttan çıkarma işlemi ile düğüm çıkarılıp gidilebilinecek komşu aranır. 


\subsection{Markov Zinciri}

Her olayın olasılığının yalnızca kendinden bir önceki olaydan edinilen bulgulara bağlı olduğu stokastik modele denir. Markov analizinde sürecin sonunda bir optimizasyon sonucu elde etmekten ziyade karar durumlarında karar vermeye yardımcı olacak nitelikte olasılıklı bilgiler sunulması hedeflenir (Alp, 2007).

Markov zincirinde şu anki durum üzerinde geçmişteki olayların etkisi yoktur denirken şu anki durum gelecekteki olayları etkileyebilir diye bakılır.

Markov zincirleri çeşitli şekillerde gösterilebilir (Karlin, 2014). Bunlardan biri matris ile gösterimdir (Tablo 2). Buna geçiş olasılıkları matrisi denir ve bu matrisin her satırı toplamı 1 dir. Matris tek yönlüdür. Örneğin Tablo 2'de V1' den V2' ye olas1lık değeri 0.4 iken V2' den V1' e 0.1538 olduğu görülmektedir. Yine Tablo 2' de görüldügüü üzre satır bazında toplamlar 1 dir (olasıllıklar toplamı).

\section{Sosyal Ağlardaki Güven Sorunsalı}

Bir ağ çok sayıda kullanıcıdan oluştuğundan bunların çoğu birbirleri hakkında fikir sahibi değildir. Kullanıcılar, kullanıcı bilgilerini kötüye kullanabilir. Böylece sosyal ağda, kullanıcı için kimin güvenilir olduğunu belirleme sorunuyla karşı karşıya kalınmaktadır. Bu nedenle, bilgi alışverişi için kullanıcılar arasındaki güvenin belirlenmesi çok önemlidir. Bilgilerin güvenilmeyen kullanıcılardan korunması, sosyal ağda çok önemli bir unsurdur (Mayadunna ve diğerleri, 2018; Goyal ve diğerleri, 2020).

$\mathrm{Bu}$ çalışmada, kullanıcıların güvenilirliğini bularak kullanıcı mahremiyetinin ve gizliliğinin korunmasını amaçlanmıştır. Güvenilmeyen bireyin tespiti ve böylelikle güvenilmeyen bir kullanıcıdan gelen bilgilerin engellenmesi, sosyal ağı güvenli ve özel hale getirecektir.

\section{Uygulanan Yöntem}

Düğümlerin ortak paylaşımları, ortak komşuları vs. çoksa bu düğümler benzerdir, yakın ilişkilidir veya başka bir deyişle birbirlerine güven duyarlar denebilir. Dügümlerin komşuları aynı ise kendileri komşu olmasalar bile benzerdirler denilebilir. Örneğin atıf analizi yaklaşımlarında da bu mantıktan faydalanılmaktadır. Bunun dışında iki düğüm arasındaki bağımsız yolların sayısının ölçülmesi, en kısa yolun mesafesi veya rastgele yürüyüş gibi yöntemlerle de dügümler arası benzerlikler saptanabilir (Fortunato, 2010).

Ağdaki diğer elemanların güvenilirlikleri sayısal olarak açıkça ifade edilebilinirse ve somut deliller ortaya konursa o elemanla güvenilirliği ölçütünde ilişki kurma yolu açılır ve dikkatli hareket edilebilinir. Yapılan çalışmada sosyal ağda bireyler arasındaki ilişki sayısal güven değerleri olarak belirlenmiştir.

$\mathrm{Bu}$ çalışmada yöntem işleyişinde sosyal ağın modeli oluşturulmasıyla işlemlere başlanır. Modelin tasarımı sırasında, olasılık tabanlı çizge modeli olan Markov Modelleri ve çizge teorisinden yararlanılmıştır. Sosyal ağ bir çizge olarak modellenmiştir. Daha sonra çizgenin bitişiklik matrisi (adjancency matrix) bulunmuştur.

Bitişiklik matrisi çizgedeki (ağırlıksız) $n$ tane dügüm için oluşturulan $n \times n$ boyutundaki matrisde birbiri ile komşu olan düğümlerin ağırlıklarının 1 olarak kabul edilip yazılması ve eğer komşu değilse 0 değerinin atanması sonucu oluşturulan matristir.

Şekil 1' de çizge olarak temsili yapılan basit bir ağırlıklı sosyal ağ gösterilmiş̧tir. Tablo 1' de bu basit çizgenin düğüm ve ayrıtlarından oluşan ve ağırlıklarının gösterildiği bitişiklik matrisi gösterilmiştir. 


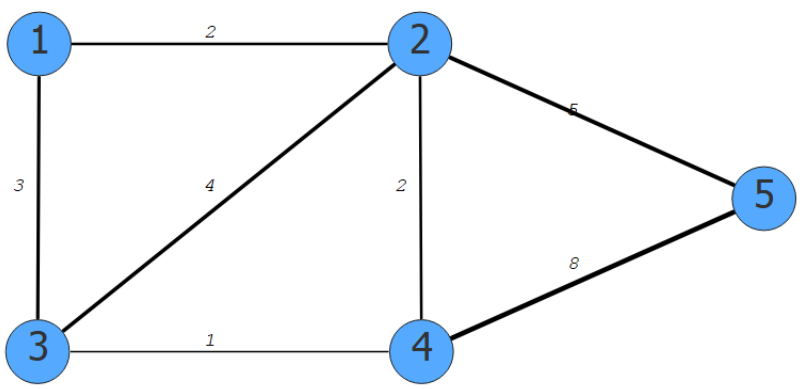

Şekil 1. Örnek bir çizge

Tablo 1. Örnek çizgenin bitişiklik matrisi

\begin{tabular}{|l|l|l|l|l|l|}
\hline Actor $^{\text {Actor }}$ & $\mathbf{V 1}$ & $\mathbf{V 2}$ & $\mathbf{V 3}$ & $\mathbf{V 4}$ & $\mathbf{V 5}$ \\
\hline V1 & 0 & 2 & 3 & 0 & 0 \\
\hline V2 & 2 & 0 & 4 & 2 & 5 \\
\hline V3 & 3 & 4 & 0 & 1 & 0 \\
\hline V4 & 0 & 2 & 1 & 0 & 8 \\
\hline V5 & 0 & 5 & 0 & 8 & 0 \\
\hline
\end{tabular}

Daha sonra Markov zinciri çizgeye uygulanarak, her satır toplamının 1 olduğu (olasılıklar toplamı) bireyler arası ilişkilerin temsili bir olasılıklar matrisi oluşturulmuştur (Tablo 2).

Tablo 2. Markov zinciri

\begin{tabular}{|l|l|l|l|l|l|}
\hline Actor $^{\text {Actor }}$ & $\mathbf{V 1}$ & $\mathbf{V 2}$ & $\mathbf{V 3}$ & $\mathbf{V 4}$ & $\mathbf{V 5}$ \\
\hline V1 & 0 & 0.4 & 0.6 & 0 & 0 \\
\hline V2 & 0.1538 & 0 & 0.3077 & 0.1538 & 0.3846 \\
\hline V3 & 0.3750 & 0.5 & 0 & 0.1250 & 0 \\
\hline V4 & 0 & 0.1818 & 0.0909 & 0 & 0.7273 \\
\hline V5 & 0 & 0.3846 & 0 & 0.6154 & 0 \\
\hline
\end{tabular}

Bundan sonra ki aşamada çizgedeki bireylerin birbirlerine duydukları güveni tespit edebilmek için bir algoritma geliştirilmiştir. Örneğin V4' ün V1' e olan güvenini bulalım. Bunun için önerilen yöntemde V4' den V1' e giden tüm yollar bulunup bu yolların olasilıkları hesaplanmıştır ve bunlar toplanırsa sonuçta bulunan değerin V4' ün V1' e duyduğu güven olduğu düşünülmüştür.

Tüm bunlar için öncelikle iki düğüm arasında ki tüm yolları listeleme ihtiyacı oluşmuştur. Bunun için yapılan literatür taramalarında çizgedeki tüm yolları bulan bir algoritma olmadığı tespit edilmiştir. Örneğin dijkstra algoritması çizgedeki en kısa yolu bulurken gezgin satıcı ile optimum yol bulunmaktadır.

Çizgede tüm yolları bulmak için DFS algoritmasının çalışma mantığından yola çıkılarak bir yöntem önerilmiştir. Yolculuğa kaynaktan başlanır. Ziyaret edilen düğümleri "yol[]" isminde bir dizide saklayarak devam edilir. Hedef düğüme ulaşılırsa yol[] dizisinin içeriği yazdırılır. Önemli olan, yol[] dizisindeki düğümleri ziyaret edildi şeklinde işaretlemektir. Böylece yolculuk bir döngüye girmez. Bu yöntem uygulanarak iki düğüm arası tüm yollar bulunmuştur. Örneğin V4' den V1' e giden tüm yollar; 
$\mathrm{a} 1=[4,5,2,3,1]$

$\mathrm{a} 2=[4,5,2,1]$;

a3=[4, 2, 3, 1];

$\mathrm{a} 4=[4,2,1]$;

a5 $=[4,3,1]$;

$\mathrm{a} 6=[4,3,2,1]$;

şeklindedir. a4 yolu olasılı̆̆ını Şekil 2' de ki markov zincirini kullanarak hesaplayalım.

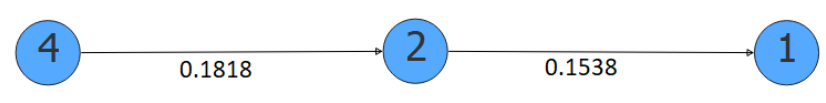

Şekil 2. a4

$\mathrm{P}(\mathrm{a} 4)=0.027$

Benzer şekilde tüm yolların olasılıkları bulunur. Bulunan olasılıklar toplanarak ve o düğüme duyulan güven oranı bulunmuştur denilebilir. V4'ün diğer düğünlere duyduğu güven oranları şöyledir;

$\mathrm{P}(\mathrm{V} 4 \mathrm{~V} 1)=0.5206$

$\mathrm{P}(\mathrm{V} 4 \mathrm{~V} 2)=0.1653$

$\mathrm{P}(\mathrm{V} 4 \mathrm{~V} 3)=0.2168$

$\mathrm{P}(\mathrm{V} 4 \mathrm{~V} 5)=0.8199$

V4' ün diğer düğümlere duyduğu güven oranlarına göre Şekil 3' de ki çizge renklendirilmiştir (En güvenilen en koyu renk).

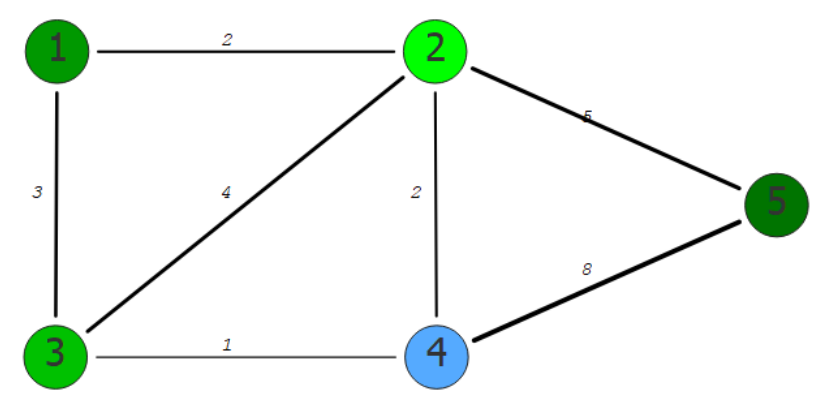

Şekil 3. V4 ün diğer düğümlere güven oranları

Benzer işlemler her düğüm çiftleri için uygulanırsa ağdaki en güvenilir ve en güvenilmez bireylerin tespiti mümkün olunur. Ağdaki tüm düğümlerin ayrı ayrı güven oranları aşağıda verilmiştir.
$\mathrm{GO}(\mathrm{V} 1)=1,3087$
$\mathrm{GO}(\mathrm{V} 2)=1,2435$
$\mathrm{GO}(\mathrm{V} 3)=1,5748$
$\mathrm{GO}(\mathrm{V} 4)=1,7226$
$\mathrm{GO}(\mathrm{V} 5)=1,019$ 
Buradan yola çıkarak ağdaki en güvenilen bireyin V4 en güvenilmez olanın ise V5 olduğu söylenebilir. Şekil 4' de güven oranları doğrultusunda renklendirme yapılmış çizge vardır (En güvenilir en koyu yeşil, en güvenilmez en açık yeşil).

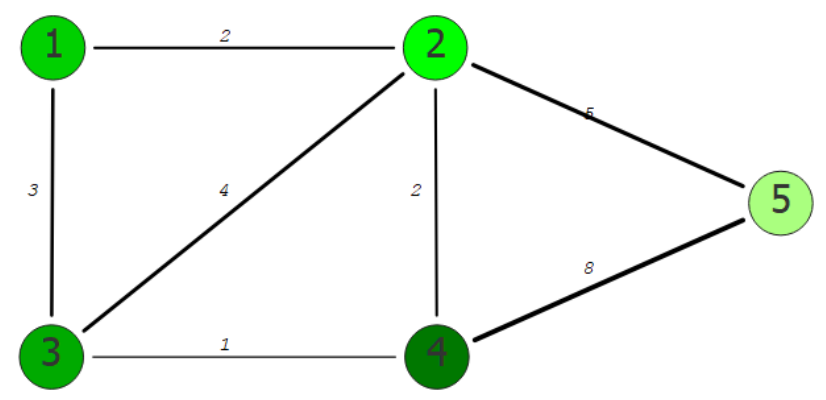

Şekil 4. Güven oranlarına göre renklendirilmiş çizge

\section{Sonuç}

Sosyal ağlarda güven sorunsalına çözüm olarak bir yöntem geliştirip bu yöntem aracıllı̆ı̀la hem ağdaki bireylerin birbirlerine duydukları güven oranları belirlenmiştir hem de ağın en güvenilir bireyi ile en güvenilmez bireyleri tespit edilmiştir.

Böylelikle sosyal ağda güvenilmez veya güven oranı düşük diye etiketlenen birey, aktör, yapı vs. için gerekli tedbirler alınabilmesi, önlemleri o yap1 üzerine yönlendirerek ağın güvenliğinin sağlanmasına olanak sağlanmıştır.

\section{Kaynakça}

Alp, S. (2007). Türkiye'de eğitim sürecinin Markov geçiş modeli. 8. Türkiye Ekonometri ve İstatistik Kongresi, 24-25.

Biggs, N., Lloyd, E. K., \& Wilson, R. J. (1986). Graph Theory, 1736-1936. Oxford University Press.

Boy, O. (2012). Sosyal ağlarda topluluk yapılarının analizi (Master's thesis, İnönü Üniversitesi Fen Bilimleri Enstitüsü).

Bruhn, M., Schoenmueller, V., \& Schäfer, D. B. (2012). Are social media replacing traditional media in terms of brand equity creation?. Management research review.

Even, S. (2011). Graph algorithms. Cambridge University Press.

Fortunato, S. (2010). Community detection in graphs. Physics reports, 486(3-5), 75-174.

Goyal, R., Upadhyay, A. K., Sharma, S., \& Mishra, P. K. (2020). Analysis of Predicting Trust in Complex Online Social Networks. Materials Today: Proceedings, 29, 573-580.

Herman, I., Melançon, G., \& Marshall, M. S. (2000). Graph visualization and navigation in information visualization: A survey. IEEE Transactions on visualization and computer graphics, 6(1), 24-43.

Karadeniz, E., TEMEL, M. M., \& KARCI, A. (2018, September). Prediction of Collaboration Between Universities of Turkey. In 2018 International Conference on Artificial Intelligence and Data Processing (IDAP) (pp. 1-4). IEEE.

Karlin, S. (2014). A first course in stochastic processes. Academic press.

Mayadunna, H., \& Rupasinghe, L. (2018, October). A trust evaluation model for online social networks. In 2018 National Information Technology Conference (NITC) (pp. 1-6). IEEE. 